\title{
PROMOSI DAN INFORMASI PADA MEDIA VIDEO PROFILE SMA MANDIRI BALARAJA
}

\author{
Ria Wulandari ${ }^{1}$ \\ Achmad Rachmat ${ }^{2}$ \\ Bobby Aditya Nugraha ${ }^{3}$ \\ Dosen STMIK Raharja ${ }^{1}$, Dosen AMIK Raharja Informatika ${ }^{2}$, STMIK Raharja Jurusan Teknik \\ Informatika $^{3}$ \\ Jl. Jendral Sudirman No. 40, Modern Cikokol, Tangerang \\ Email : wulandari@raharja.info ${ }^{1)}$, achmad.rachmat@raharja.info ${ }^{2)}, \underline{\text { bobby.aditya@raharja.info }}{ }^{3)}$
}

\begin{abstract}
ABSTRAK
Akses informasi sangat penting, karena adanya informasi semua orang akan mengetahuinya. SMA Mandiri Balaraja memiliki Fasilitas yang banyak dan dan memiliki cara belacar yang berbeda. SMA Mandiri Balaraja merupakan pendidikan untuk mempromosikan sekolah SMA Mandiri Balaraja kabupaten tangerang. Saat ini SMA Mandiri Balaraja belum memiliki suatu media informasi yang menjelaskan secara detail untuk mendaftar dan mengenal fasilitas yang ada di SMA Mandiri Balaraja. Video yang dirancang ini menjelaskan keunggulan belajar, fasilitas sekolah, gedung yang luas, ekstrakulikuler yang banyak, untuk mengetahui informasi dan promosi SMA Mandiri Balaraja. Tujuan mencapai target sekolah SMA Mandiri Balaraja dalam hal menyampaikan informasi dan promosi tentang sekolah SMA Mandiri Balaraja, serta meningkatkan jumlah siswa yang akan mendaftar di SMA Mandiri Balaraja setiap tahunnya. Adapun metode penelitian ini diantaranya Pengumpulan Data, Analisa Perancangan Media, dan Konsep Produksi Media : pre production, production,dan post production. Melalui media informasi dan promosi SMA Mandiri Balaraja yang dirancang akan di informasikan melalui : Youtube, Website SMA Mandiri Balaraja dan facebook. Target yang diharapkan SMA Mandiri Balaraja yaitu, calon siswa dan siswi yang akan mendaftar di SMA Mandiri Balaraja dan masyarakat dapat mengetahui SMA Mandiri Balaraja kabupaten Tangerang, serta dapat meningkatkan jumlah calon siswa dan siswi yang berkunjung ke SMA Mandiri Balaraja setiap tahunnya.
\end{abstract}

Kata Kunci : Video, Informasi, Promosi

\section{ABSTRACT}

Access to information is now a very important thing, because the information everyone will know. SMA Mandiri Balaraja has many facilities and and has different belacar way. SMA Mandiri Balaraja is an education that has the authority to promote SMA SMA Mandiri Balaraja tangerang district. Currently SMA Mandiri Balaraja not have a media information that explains in detail that can attract prospective students to register and recognize the existing facilities in SMA Mandiri Balaraja. This designed information and promotional video explains the excellence of learning, school facilities, extensive building, extracurricular activities at the present time, so it can be an attraction for prospective students and high school students of Balaraja Mandiri as well as the community, to find out information and promotion of SMA Mandiri Balaraja. The purpose of this study is to achieve the target of SMA Balaraja Mandiri High School in terms of conveying information and promotion about SMA Mandiri Balaraja, and increasing the number of prospective students and students who will enroll in SMA Mandiri Balaraja every year. The research methods used in this study include Data Collection, Media Design Analysis, and Concept Media Production (KPM) which includes: pre production, production, and post production. Through the media information and promotion SMA Mandiri Balaraja designed will be informed through: Youtube, SMA Mandiri Balaraja Website and facebook. The expected target is, prospective students and students who will enroll in SMA Mandiri Balaraja and the community can know SMA Balanganja Mandiri Tangerang district, and can increase the number of prospective students and girls who visit Balaraja Mandiri SMA every year. 


\section{PENDAHULUAN}

Dalam dunia pendidikan mempromosikan pendidikan sangatlah penting, promosi berperan menyebarkan informasi dan mempengaruhi calon siswa-siswi sehingga tertarik dengan sekolah tersebut. Banyaknya pendidikan baik swasta maupun negeri. Adanya persaingan antar sekolah untuk menambah calon siswa-siswi. jurusan pada setiap sekolah memiliki daya tarik tersendiri. Persaingan setiap sekolah membuat promosi untuk Siswa -siswi. Promosi biasanya dilakukan di SMP dan sederajat di kota-kota di tangerang. Promosi yang ada kegitan berada di kota tersebut, maka pendidikan harus tepat dalam menentukan kota tujuan sehingga tidak salah sasaran. Penentuan dilakukan tidak dalam menentukan keputusan, adanya negatif terhadap hasil promosi. Dengan adanya sarana promosi, dengan menggunakan media cetak elektronik ataupun yang lainnya sehingga adanya perkembangan teknologi sarana produksi media khususnya perkembangan teknologi multimedia.

\section{RUMUSAN MASALAH}

sekolah saat ini hanya menggunakan media desain untuk mempromosikan kepada calon siswa-siwi dan masyarakat, namun banyaknya siswa yang kurang memahami dalam mempromosikan media desain tersebut dan masyarakat informasi bisa juga adanya gagalnya proses presentasi. Karena tampilan video propfil dalam media projek menjadi lebih menarik, dan dapat di pahami calon siswa-siswi dan masyarakat tentang SMA Mandiri Balaraja Kabupaten Tangerang.

\section{LANDASAN TEORI \\ Pengertian Promosi}

suatu akitivitas komunikasi yang dilakukan oleh seseorang atau suatu perusahaan dengan masyarakat luas, dimana tujuannya adalah untuk memperkenalkan sesuatu (barang/ jasa/ merek/ perusahaan) kepada masyarakat dan sekaligus mempengaruhi masyarakat luas agar membeli dan menggunakan produk tersebut.

\section{Pengertian Video}

Teknologi untuk menangkap, merekam, memproses, mentransmisikan dan menata ulang gambar bergerak. Biasanya menggunakan film seluloid, sinyal elektronik, atau media digital. Berkaitan dengan "penglihatan dan pendengaran"

\section{Pengertian Audio}

suara yang muncul akibat getaran suatu benda (kekuatannya minimal 20 kali/detik) dan bisa ditangkap oleh telinga manusia.

\section{Pengertian Multimedia}

pemanfaatan komputer untuk membuat dan menggabungkan teks, grafik, audio, video, dengan menggunakan tool yang memungkinkan pemakai berinteraksi, berkreasi, dan berkomunikasi.

\section{Tujuan Multimedia}

kombinasi dari beragam bentuk konten seperti teks, audio, video, gambar dan animasi untuk memberikan informasi atau hiburan kepada pengguna. 


\section{Tahapan Produksi Audio Visual}

\section{Pra Produksi}

Segala kegiatan yang berhubungan dengan persiapan sebelum melakukan produksi.

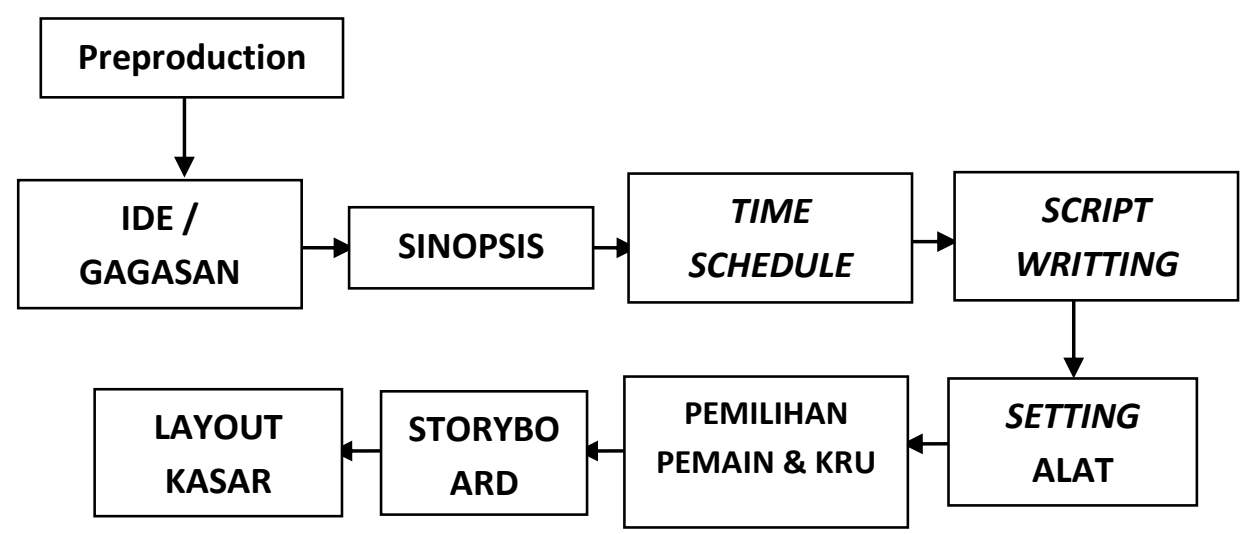

Gambar 1. Tahapan Pra Produksi

\section{Produksi}

merupakan tahap implementasi pra-produksi dimana semua anggota tim pengembang multimedia bekerja.

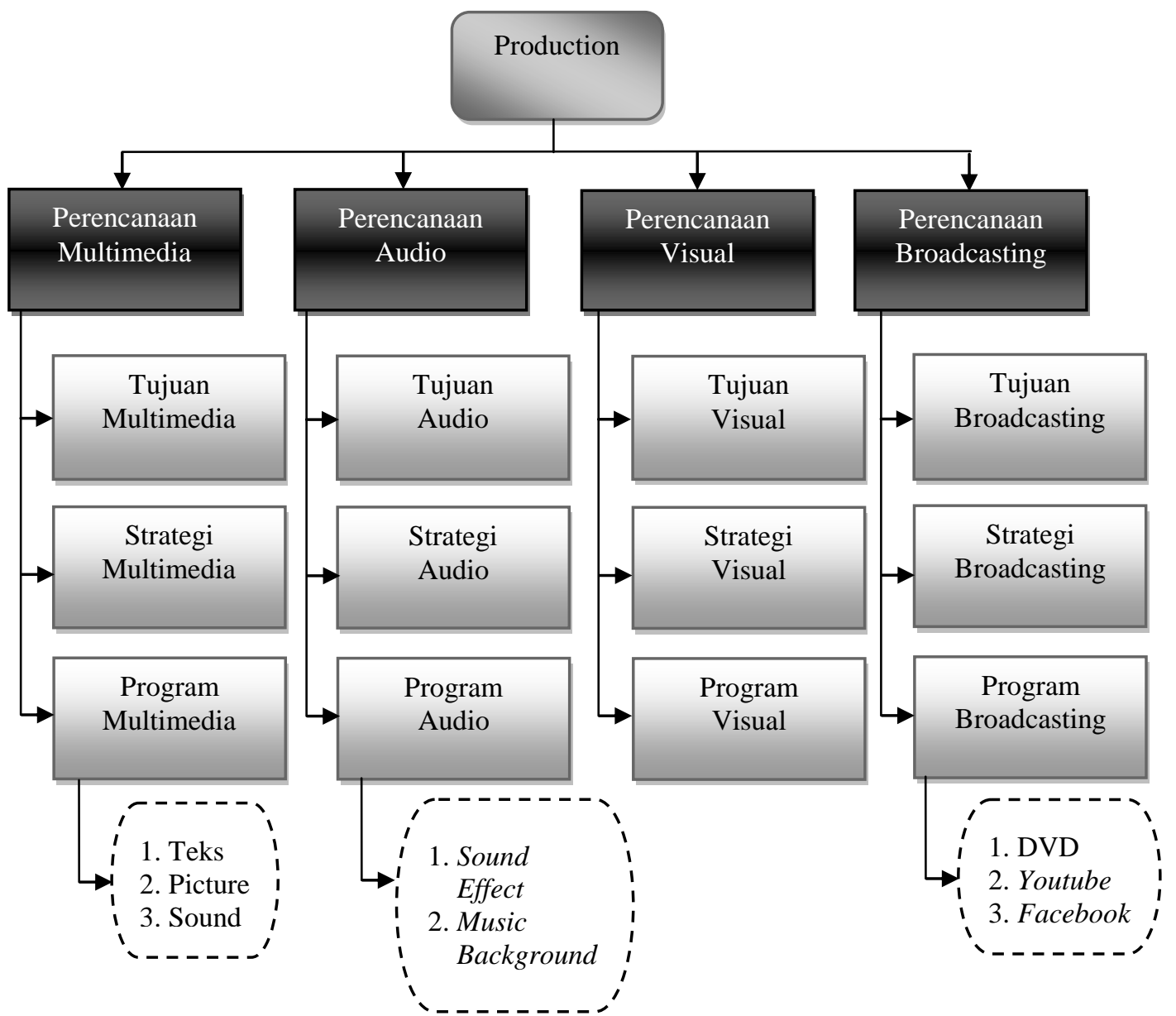

Gambar 2. Tahapan Produksi 


\section{Post Produksi}

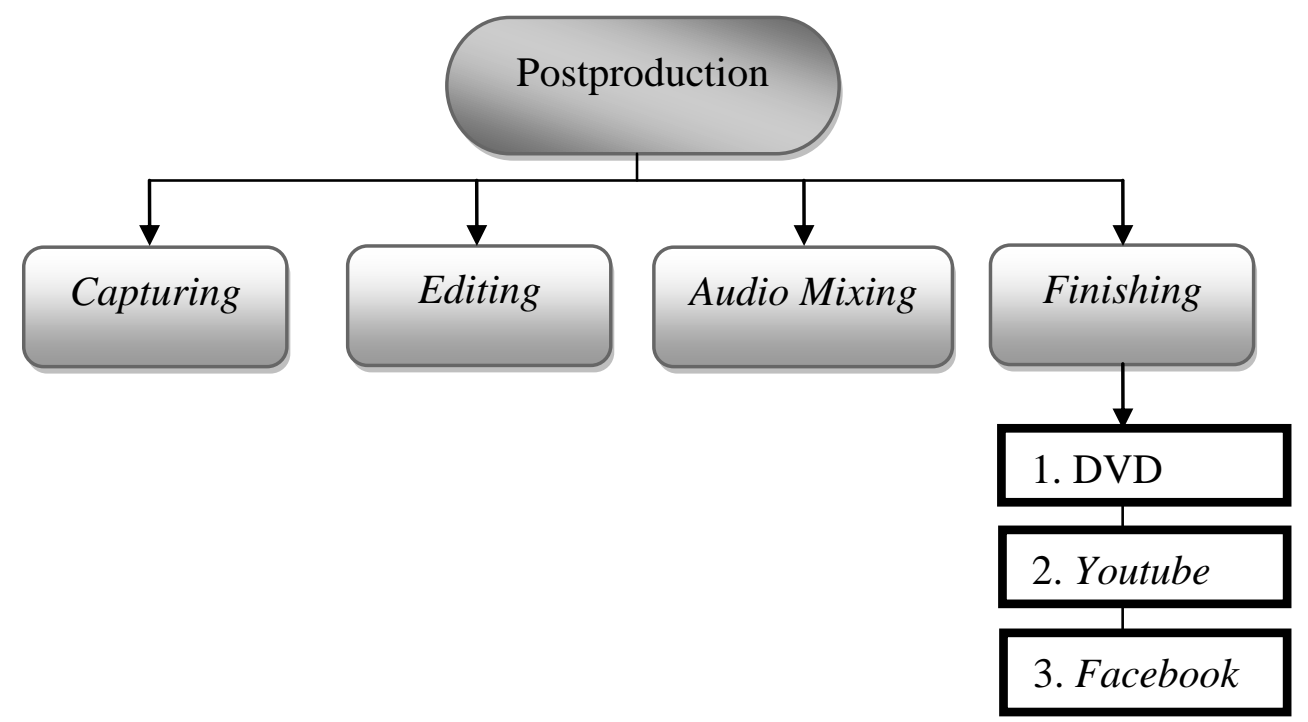

Gambar 3. Pasca Produksi

\section{Storyboard}

Scene 1

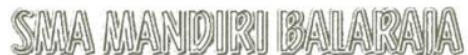

Bumper Opening Tulisan SMA Mandiri Balaraja

Gambar 4. Opening Tulisan SMA Mandiri Balaraja

\section{Scene 2}

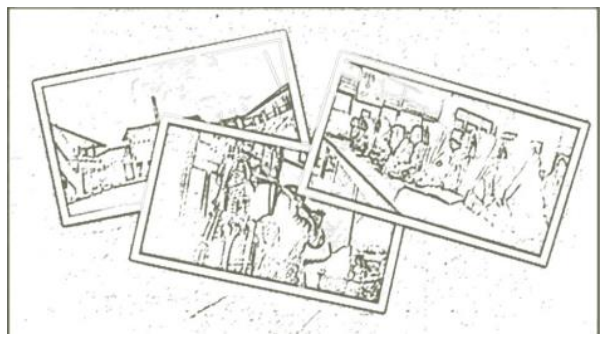

Video video opening Slide

Gambar 5. Opening video opening Slide Video 


\section{Scene 3}

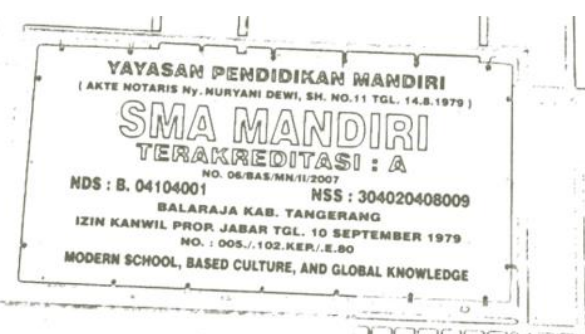

EXT / video Papan Nama SMA

Mandiri Balaraja (Medium Close

$U p)$

Gambar 6. Papan Nama SMA Mandiri Balaraja

\section{Scene 4}

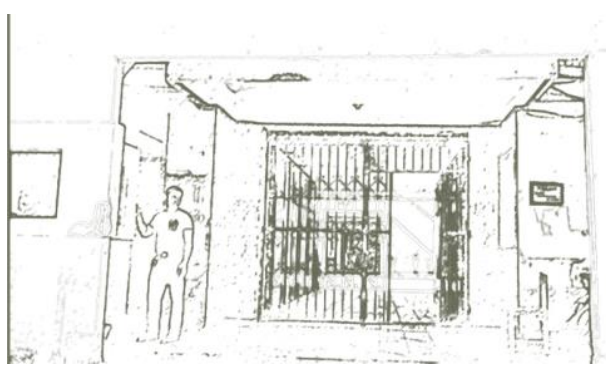

EXT / video pintu gerbang sekolah SMA Mandiri Balaraja (Full Shoot)

Gambar 7: pintu gerbang sekolah SMA Mandiri Balaraja

\section{Scane 5}

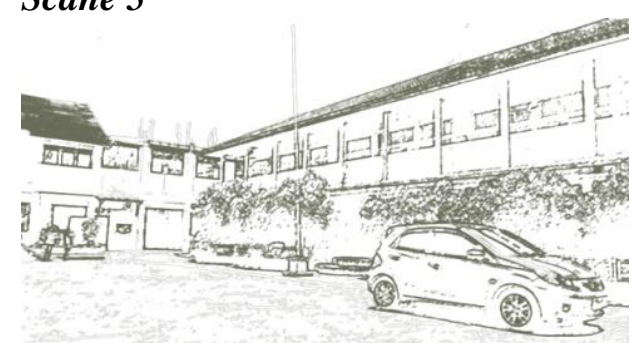

EXT / Gedung sekolah SMA

Mandiri Balaraja (Medium

Shoot)

Gambar 8. Gedung sekolah SMA Mandiri Balaraja

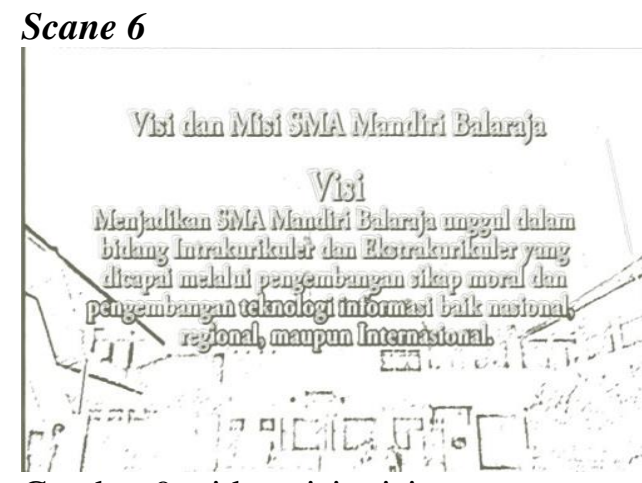

video visi misi sekolah SMA Mandiri Balaraja

Gambar 9. video visi misi 


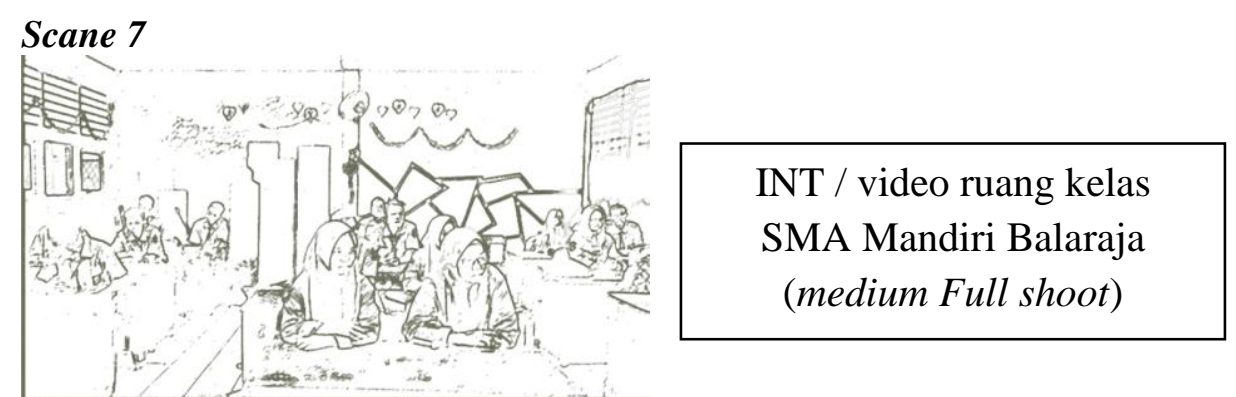

Gambar 10. ruang kelas SMA Mandiri Balaraja

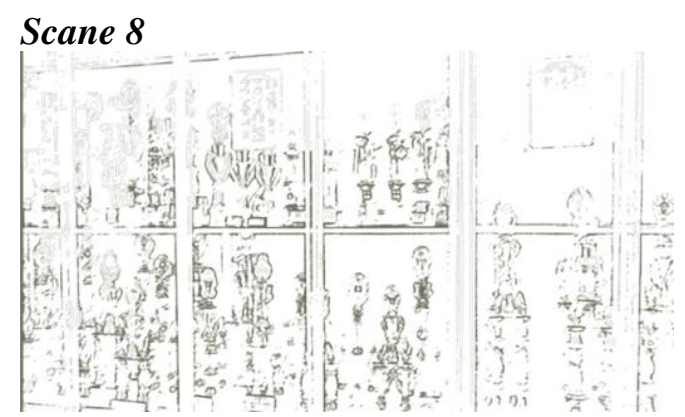

INT / Video Prestasi atau
piala SMA Mandiri Balaraja
(medium shoot)

Gambar 11. Prestasi atau piala SMA Mandiri Balaraja

\section{Adobe Premier CS3}

dikhususkan untuk merangkai gambar, video dan audio, bukan untuk animasi karena untuk animasi kita bisa memakai Adobe After Effect.

\section{Corel Video Studio X5}

paket perangkat lunak editing video oleh Ulead Systems (sebuah divisi dari Corel). Versi terbaru dari software ini X8.

\section{Adobe Photoshop CS3}

perangkat lunak untuk mengolah citra atau perangkat lunak desain grafis yang berguna untuk mengedit gambar, memberi efek gambar.

\section{LITERATUR REVEWER}

1. "Pembuatan Video Profil Sekolah Menengah Pertama Negeri 3 Karanganyar pengembangan dan penambahan media promosi yang diinginkan dalam target pemasaran yang telah diprogramkan. untuk media komunikasi video profile yaitu suatu karya video atau gambar yang dikemas berupa video profile Sekolah Menengah Pertama Negeri 3 Karanganyar, video profile yang merupakan sebagai media yang dapat di jadikan aset sekolah yang dapat digunakan untuk meningkatkan suatu image atau citra dari masyarakat.

2. "Pembuatan Video Profil Sekolah Dasar Negeri Menadi Kabupaten Pacitan Berbasis Multimedia". Mempererat pembangunan dewasa ini. karena itu pendidikan yang bermutu perlu mendapat perhatian serius dari pemerintah.

3. "Pengaruh Media Pembelajaran Video Interaktif Terhadap Hasil Belajar Siswa Pada Materi Wakaf Mata Pelajaran Al-Islam Kelas X Di Sma Muhammadiyah 1 Palembang" Persoalan yang melatar belakangi penelitian ini yaitu, kemajuan ilmu pengetahuan dan tekhnologi, khususnya 
tekhnologi informasi, sangat berpengaruh terhadap penyusunan dan implementasi pembelajaran. melalui kemajuan tersebut para guru harus dapat menggunakan berbagai media sesuai dengan kebutuhan dan tujuan pembelajaran.

4. Pengembangan Media Video Pembelajaran Sejarah Tentang Islamisasi Di Nusantarauntuk Kelas X Sma. Agus Mujib. Fakultas Ilmu Sosial, Universitas Negeri Malang. edia video pembelajaran. Sedangkan objek penelitian ini adalah siswa SMA kelas X. Validasi produk dilakukan oleh ahli materi dan ahli media. Kemudian uji coba produk dilakukan kepada guru dan siswa. Data yang diperoleh dalam uji coba ini diperoleh dari angket. Data penelitian ini berupa data verbal berupa komentar dan saran perbaikan, sedangkan data nonverbal berupa skor penilaian.

5. " Pengembangan Media Pembelajaran Berbasis Video Interaktif Pada Pembelajaran Sains Materi Ciriciri Makhluk Hidup Kelas Iii Sd It Alazhar Jambi. Firmansah Aliwardana. Fkip Universitas Jambi. Perlu Adanya Suatu Media Yang Dapat Mengatasi Permasalahan Tersebut. Tujuan Dari Penelitian Ini Adalah Untuk Menghasilkan Media Video Pembelajaran Interaktif Materi Ciri-Ciri Mahkluk Hidup Untuk Kelas Iii Sd Yang Layak Digunakan Dalam Pembelajaran, Untuk Mendeskripsikan Kelayakan Media Yang Dikembangkan Berdasarkan Data Kuantitatif Dan Kualitatif Yang Meliputi Kelayakan Isi/Materi Dan Kelayakan Desain/Media, Serta Untuk Mendeskripsikan Respon Guru Dan Siswa Terhadap Pembelajaran Dengan Menggunakan Media Video Pembelajaran Interaktif Materi Ciri-Ciri Mahkluk Hidup Di Kelas Iii Sd.

\section{KESIMPULAN}

Calon siswa siswi dalam mendapatkan informasi secara tepat dan akurat tentang SMA Mandiri Balaraja Kabupaten Tangerang Agar perancangan video profile dapat menarik perhatian calon siswa siswi dan informasi yang disampaikan lebih efektif yaitu dengan menampilkan sebuah video profile yang berisikan informasi yang berupa penjelasan detail isi video yang kreatif dan kualitasnya dapat dinikmati oleh setiap yang melihatnya. Mengenai SMA Mandiri Balaraja Kabupaten Tangerang.

\section{DAFTAR PUSTAKA}

[1] Nur Hasim Wahid, 2012, Konsep Dasar Video Profile

[2] Nurjanah Nunu, 2013, Pra Produksi

[3] Rahmet, 2012, Video Profile

[4] Ridwan Ardiansyah Aji, 2012, Pengertian Perancangan

[5] Ruslan, 2012, Kualitas Informasi

[6] Saiful Rijal Said, 2013, "PERANCANGAN MEDIA VIDEO PROFILE SEBAGAI SARANA PENUNJANG PROMOSI PADA SMKISLAM KAFAH UNGGUL"

[7] Slamet, 2012 Dalam Buku Desain Komunikasi Visual Teori Dan Aplikasi Alternatif Media

[8] Sona Rosadi Elva, 2013, "PERANCANGAN MEDIA VIDEO PROFILE SEBAGAI PENUNJANG INFORMASI DAN PROMOSI PADA SMK PGRI 1 TANGERANG".

[9] Sudrajat Dede, 2012, Produksi

[10] Sugiyono, 2012, Pengertian Data 
[11] Sunarya dkk Lusyani, 2013, Persiapan Data dan Adobe Photoshop Diktat Perkuliahan Aplikasi Program Komputer Mavib II

[12] Suyanto, 2012, Definisi Storyboard

[13] Yulianti Liana, 2012, Pengertian Video dan Adobe Premier Pro CS6 